\title{
Hypothermia Therapy After Traumatic Brain Injury: A Systematic Review and Meta-Analysis
}

\author{
Lige LENG \\ Medical College, Xiamen University, Xiamen, Fujian Province, China
}

\section{ABSTRACT}

The purpose of this article was mainly to focus on whether hypothermia improves mortality and/or the chance of a good neurological outcome compared with the standard of care alone in patients with traumatic brain injury (TBI). We used a comprehensive search strategy. Articles were eliminated in a stepwise fashion. Data from each study was entered in the Review Manager (RevMan) software version 5.0 when reported. Seven studies including 1331 patients met all selection criteria. This meta-analysis merged all data of the 7 articles to come to a conclusion. It also conducted a detailed analysis of the different classifications, trying to outline the possible mechanisms. We included two Chinese articles and tried to find out the effects of hypothermia on the Asian race. Regarding the poor outcome of hypothermia on diffuse lesions, we also analyzed the mechanism and provided our speculation. Children with traumatic brain injury were also analyzed regarding the effect of hypothermia treatment and the possible cause of the poor outcome. The results of these clinical trials were heterogeneous. Hypothermia treatment in TBI seems to provide good outcomes on focal lesions, adult patients, Asian patients and at a relatively higher temperature $\left(33-36^{\circ} \mathrm{C}\right)$.

KEYWORDS: Hypothermia, Intracranial pressure, Traumatic brain injury

\section{INTRODUCTION}

$\mathrm{T}$ Traumatic brain injury (TBI) is a primary cause of death and long-term morbidity. Induced hypothermia is now an accepted method to improve the outcome following anoxic brain injury associated with heart failure $(2,12)$, but its benefits in TBI are unclear. The effect of hypothermia on high intracranial pressure (ICP) is beneficial, but probably unrelated to its effect on the outcome. The outcome related to the intracranial pressure was evident both in patients who had normothermia on admission and whose outcome did not improve with induced hypothermia and in patients who had hypothermia at admission and whose outcome did improve with lasting hypothermia. Brain ischemia results from impaired auto-regulation, local and global hypoperfusion, elevated ICP and increased cerebral metabolic needs $(4,8)$. Reperfusion injury is due to a complex cellular cascade leading to tissue damage (13). Hypothermia may be beneficial for the injured brain not only by reducing ICP and cerebral metabolic needs $(17,19)$, but also by decreasing damage of the blood-brain barrier (BBB) (14), and inhibiting the inflammatory cascade that may lead to reperfusion injury $(3,18)$. There had been some meta-analysis included in these 7 articles before, but none of them refined or classified these articles. This metaanalysis will also get all data of 7 articles together to come to a conclusion and it will carry out a detailed analysis of the different classifications, trying to outline the possible mechanisms. For example, in this meta-analysis, we included two Chinese articles, trying to find out the effects of hypothermia on the Asian race. For the poor outcome of hypothermia of diffuse lesions, we also analyzed the mechanisms and provided our speculation. Children with TBI were also analyzed for the effect of hypothermia treatment and the possible cause of the poor outcome. 


\section{QUESTION}

The purpose of this review was to answer the following question: In patients with TBI without major contraindications (e.g., hypotension, ongoing hemorrhage), does mild-tomoderate $\left(32^{\circ}-36^{\circ} \mathrm{C}\right)$ hypothermia, in addition to standard of care, improve mortality and/or the chance of a good neurological outcome (Glasgow Outcome Scale [GOS] score) at a specified time after rehabilitation, compared with the standard of care alone? The GOS is a widely used 5-point scale measuring neurological outcome where 1 indicates death, 2-3 indicates vegetative state or dependent living, and 4-5 indicates independent living or return to work/school.

\section{MATERIAL and METHODS}

\section{Search Strategy and Selection Criteria}

We followed the recommendations of the Cochrane Handbook for Systematic Reviews of Interventions and the QUOROM (quality of reporting of meta-analyses) statement in this meta-analysis. We developed a comprehensive search strategy and using the database with appropriate keywords, searched the MEDLINE, Pubmed clinical trials, Web of Science, the Cochrane Central Register of Controlled Trials, the Cochrane Database of Systematic Reviews, Papers First and Proceedings First. In addition, we hand-searched conference proceedings, abstracts and the bibliographies of other literature reviews and of all short-listed studies.

\section{Data Extraction and Quality Assessment}

Articles were then eliminated in stepwise fashion (Figure 1). First the duplicates were eliminated and then we eliminated clearly irrelevant papers that did not meet our inclusion criteria based on the title or abstract. The remaining papers were retrieved for full-text review by 1 reviewer and short-listed for final review if the reviewer could not eliminate the possibility that the paper was a clinical trial of hypothermia for TBI. All short-listed papers that had not been eliminated by this stage were reviewed in their entirety by 2 independent reviewers according to an a priori protocol. We assessed agreement on inclusion and exclusion between the 2 reviewers as a simple ratio of studies agreed on to total studies assessed. Data in the form of mortality and dichotomized GOS were extracted in duplicate by 2 independent reviewers.

\section{Data Analysis}

Data from each study was entered in the Review Manager (RevMan) software version 5.0 for Windows (The Nordic Cochrane Centre, The Cochrane Collaboration). As there was significant clinical heterogeneity among the studies, we chose to perform a random effects meta-analysis using RevMan to calculate relative risk (RR) and absolute risk with $95 \%$ confidence intervals (Cls) for mortality. We tested for the presence of statistical heterogeneity using the $x^{2}$ test and $l^{2}$ value, using a priori-defined cutoffs of $\mathrm{p}<0.10$ or $I^{2}>50 \%$. In case these cutoffs were surpassed, we planned



Figure 1: Flow chart showing the elimination of articles. 
sensitivity analyses with low-quality studies removed. We also constructed a funnel plot to assess the likelihood of publication bias.

\section{RESULTS}

Seven studies including 1331 patients met all selection criteria and were identified (Table I) $(1,6,7,10,11,15,20)$. Of these 7 trials, 2 were conducted in China and the remaining five were conducted as multicenter studies in many countries. Six trials compared the effect of hypothermia treatment versus regular treatment. One trial divided the patients into three groups. One group was induced hypothermia, at $35-36^{\circ} \mathrm{C}$; one group mild hypothermia, at $33-34^{\circ} \mathrm{C}$; and one group normal temperature. In order to make a comprehensive analysis, we will define the first two groups as one hypothermia group.

All 7 studies included mortality data and also had data on functional outcome (dichotomized GOS). All 7 studies evaluated a short-term (24-48 hours) cooling strategy. There was significant heterogeneity among studies in the following areas: study quality, outcome assessment blinding described in $4 / 6$ studies, various depth/duration of hypothermia and criteria for re-warming in hypothermia protocols, and variations in the control group mortality (Table I). None of the pooled estimates met the a priori criteria for statistical heterogeneity (Figures 2, 3). When data from 7 included studies were pooled, there was no statistical difference for patients receiving hypothermia for mortality (RR 1.21, 95\% Cl 0.93-1.57) and also no statistical difference for good neurological outcome (GOS score of 4 or 5) (RR1.00, 95\% Cl 0.80-1.21) (Figures 2, 3).

Two Chinese studies showed that hypothermia treatment had better effects on Asian patients, and this seems related to controlled hypothermia at a little higher temperature $\left(33-36^{\circ} \mathrm{C}\right)$ $(10,20)$.

Clifton et al. discovered that there was a significant interaction between treatment and presence of surgically removed haematoma compared with diffuse brain injury $(p=0.001)(7)$. We tried to analyze the possible reasons (Figure 4).

Hutchison et al. indicated that in children with severe TBI, hypothermia therapy that is initiated within 8 hours after injury and continued for 24 hours does not improve the neurologic outcome and may increase mortality (11). We also tried to analyze the possible mechanism (Figure 5).

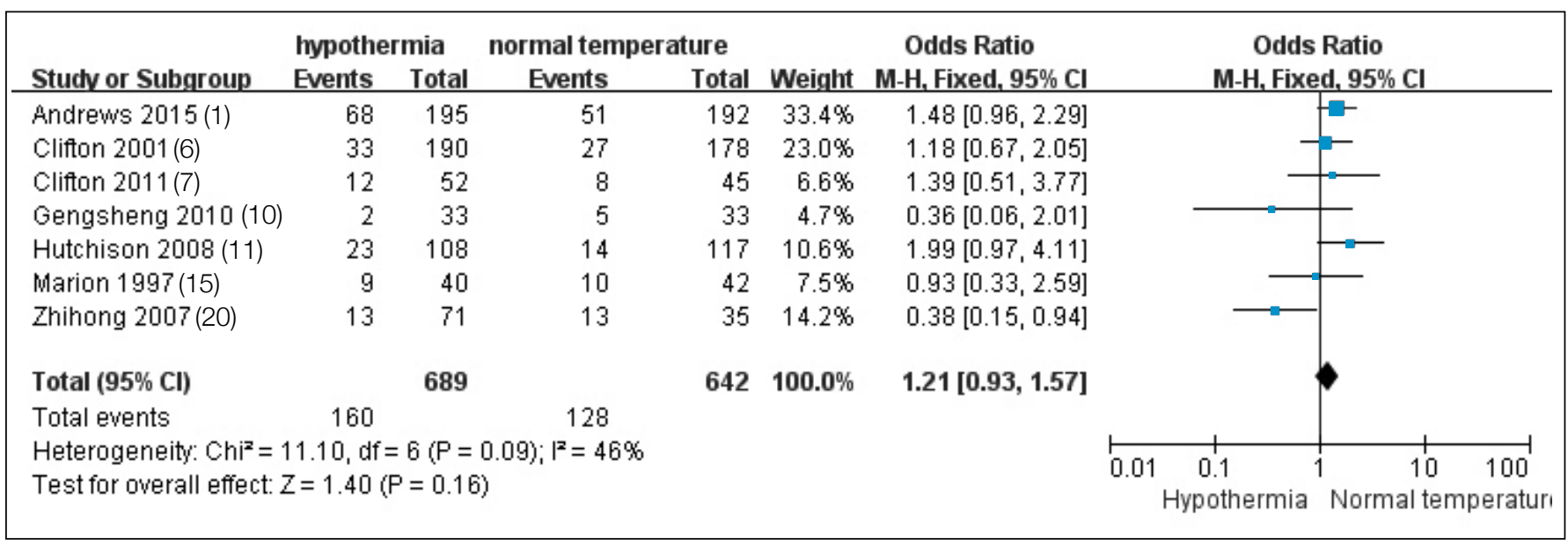

Figure 2: Forest plot showing relative risk of mortality in trials of hypothermia compared with standard therapy.

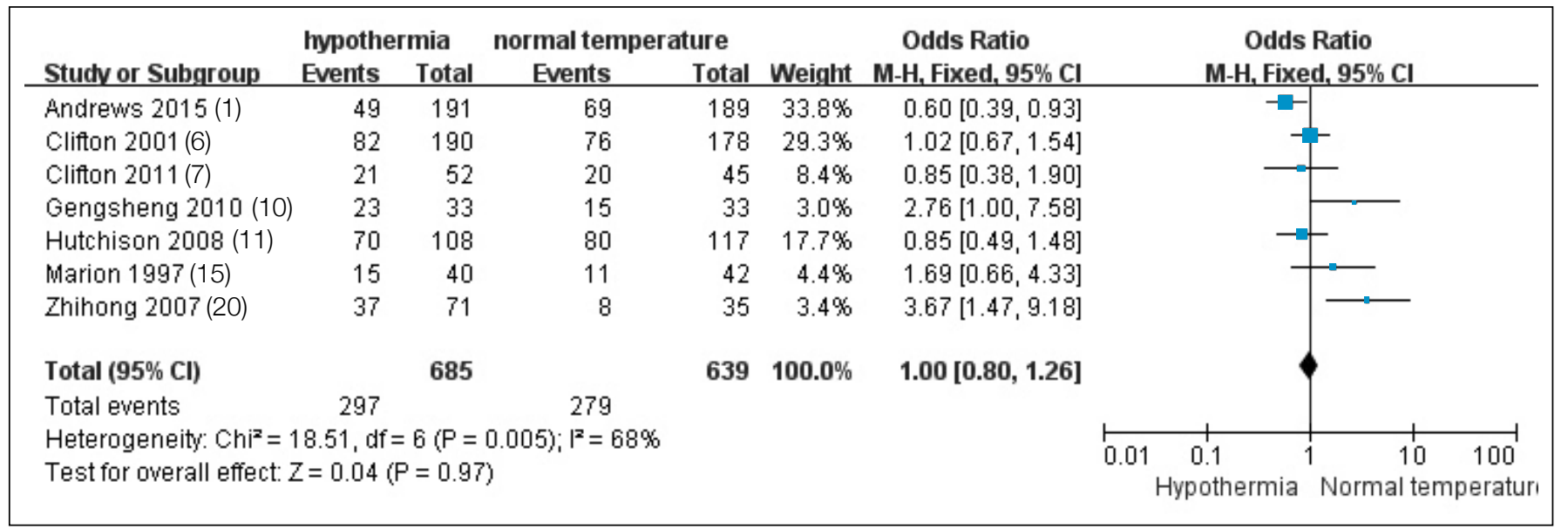

Figure 3: Forest plot showing relative risk of good neurologic outcome in trials of hypothermia compared with standard therapy. 
Table I: Summary of Included Studies

(a) Characteristics of included studies

\begin{tabular}{|c|c|c|c|c|c|c|}
\hline Study & Population & Inclusion criteria & $\begin{array}{l}\text { Time to target } \\
\text { temperature }\end{array}$ & $\begin{array}{c}\text { Target } \\
\text { temperature }\end{array}$ & Duration & $\begin{array}{c}\text { Rewarming } \\
\text { time }\end{array}$ \\
\hline $\begin{array}{l}\text { Andrews } \\
2015 \text { (1) }\end{array}$ & $\begin{array}{c}387 \text { (195 for hypothermia } \\
\text { treatment; } 192 \text { at normal } \\
\text { temperature) }\end{array}$ & $\begin{array}{l}\text { ICP of more than } \\
20 \mathrm{~mm} \mathrm{Hg}\end{array}$ & not mentioned & $32 \sim 35^{\circ} \mathrm{C}$ & $\begin{array}{l}\text { More than } \\
48 \mathrm{~h}\end{array}$ & $0.25^{\circ} \mathrm{C} / \mathrm{h}$ \\
\hline Clifton 2001 (6) & $\begin{array}{c}368 \text { (190 for hypothermia } \\
\text { treatment; } 178 \text { at normal } \\
\text { temperature) }\end{array}$ & $\begin{array}{c}\text { Glasgow Coma } \\
\text { Scale [GCS] score } \\
\leq 8\end{array}$ & $8.4 \pm 3.0 \mathrm{~h}$ & $33^{\circ} \mathrm{C}$ & $47.2 \pm 3.0 h$ & $18.1 \pm 7.0 \mathrm{~h}$ \\
\hline Clifton 2011 (7) & $\begin{array}{c}97 \text { (52 for hypothermia } \\
\text { treatment; } 45 \text { at normal } \\
\text { temperature) }\end{array}$ & $\begin{array}{c}\text { Glasgow Coma } \\
\text { Scale [GCS] score } \\
\leq 8\end{array}$ & not mentioned & $33^{\circ} \mathrm{C}$ & $48 \mathrm{~h}$ & $8 \mathrm{~h}$ \\
\hline $\begin{array}{l}\text { Hutchison } 2008 \\
\text { (11) }\end{array}$ & $\begin{array}{c}225 \text { (108 for hypothermia } \\
\text { treatment; } 117 \text { at normal } \\
\text { temperature) }\end{array}$ & $\begin{array}{c}\text { Glasgow Coma } \\
\text { Scale [GCS] score } \\
\leq 8\end{array}$ & not mentioned & $32.5 \pm 0.5^{\circ} \mathrm{C}$ & $24 h$ & $8 \mathrm{~h}$ \\
\hline $\begin{array}{l}\text { Zhihong } 2007 \\
\text { (20) }\end{array}$ & $\begin{array}{c}106\left(36 \text { at } 35 \sim 36^{\circ} \mathrm{C} ;\right. \\
35 \text { at } 33-34^{\circ} \mathrm{C} ; 35 \text { at normal } \\
\text { temperature })\end{array}$ & $\begin{array}{c}\text { Glasgow Coma } \\
\text { Scale [GCS] score } \\
\leq 8\end{array}$ & $4 \sim 6 h$ & $\begin{array}{l}35 \sim 36^{\circ} \mathrm{C} \\
33-34^{\circ} \mathrm{C}\end{array}$ & $\begin{array}{l}\text { according to } \\
\text { ICP }\end{array}$ & $\begin{array}{c}\text { Natural } \\
\text { rewarming }\end{array}$ \\
\hline $\begin{array}{l}\text { Gengsheng } \\
2010(10)\end{array}$ & $\begin{array}{c}66 \text { (33 for hypothermia } \\
\text { treatment; } 33 \text { at normal } \\
\text { temperature) }\end{array}$ & $\begin{array}{c}\text { Glasgow Coma } \\
\text { Scale [GCS] score } \\
\leq 8\end{array}$ & $3 h$ & $32-34^{\circ} \mathrm{C}$ & $\begin{array}{l}\text { according to } \\
\text { ICP }\end{array}$ & $\begin{array}{c}\text { Natural } \\
\text { rewarming }\end{array}$ \\
\hline
\end{tabular}

(b) Results of included studies

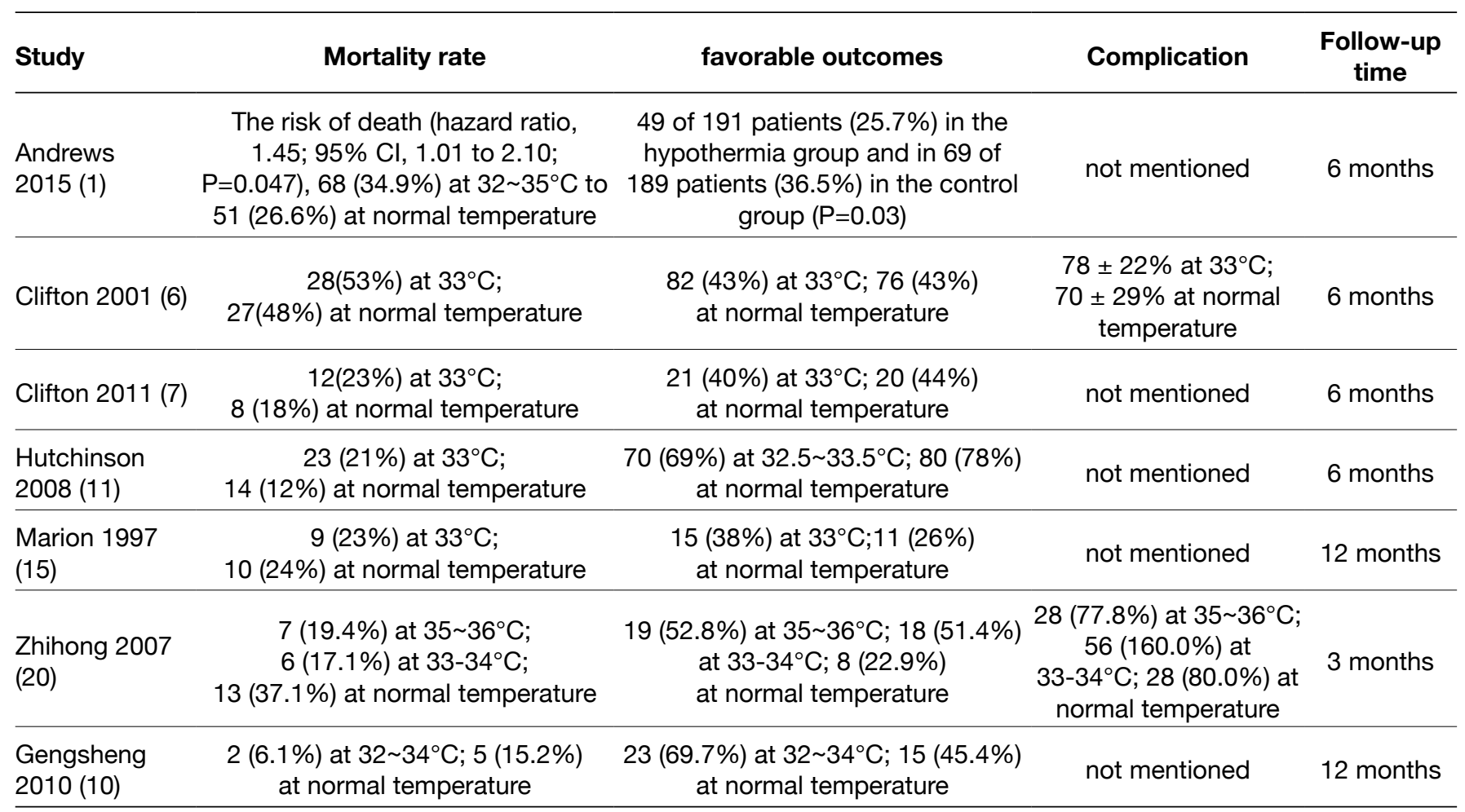



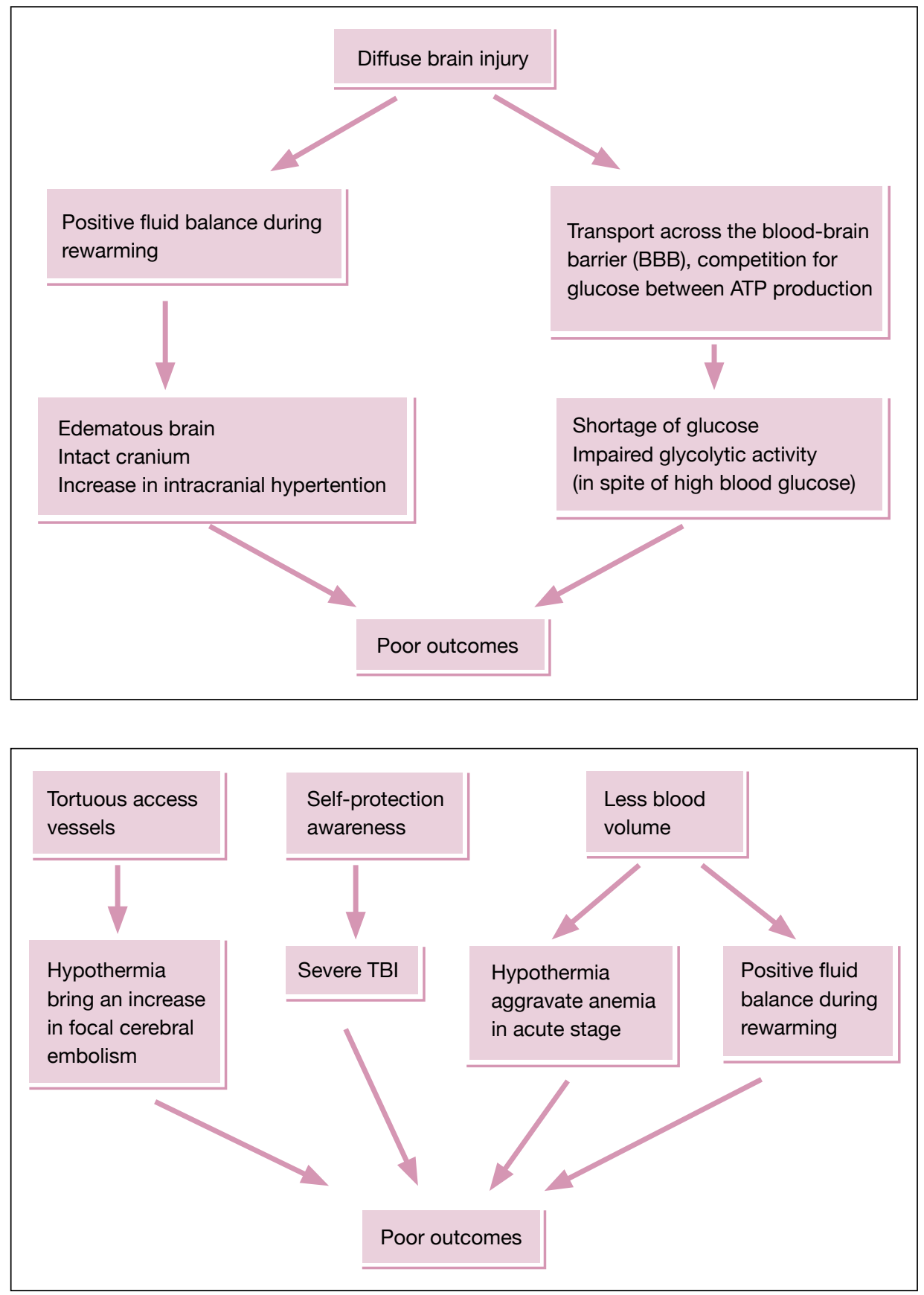

Figure 4: Possible mechanism of poor outcomes of diffuse brain injury by hypothermia treatment.
Figure 5: Possible mechanism of poor outcomes in childhood TBI by hypothermia treatment.
There was much variability in adverse events reported by studies in this meta-analysis. Clifton et al. found that $10 \%$ of the patients in the hypothermia group and $3 \%$ of those in the normothermia group had critical hypotension (a mean arterial pressure of less than $70 \mathrm{~mm} \mathrm{Hg}$ associated with organ failure) for two or more consecutive hours $(p=0.01)$ (6). Bradycardia associated with hypotension for two or more consecutive hours occurred in $16 \%$ of the patients in the hypothermia group and $4 \%$ of the patients in the normothermia group $(p=0.04)$. The percentage of hospital days on which any complication was recorded was $78 \pm 22 \%$ for patients in the hypothermia group and $70 \pm 29 \%$ for patients in the normothermia group $(p=0.005)$.
Zhihong et al. (20) found complication recorded $77.8 \%$ (at 35$36^{\circ} \mathrm{C}$ ) and $160.0 \%$ (at $33-34^{\circ} \mathrm{C}$ ) for patients in the hypothermia group and $80.0 \%$ for patients in the normothermia group. Clifton et al. found that there were no significant differences in the percentage of patients with any individual complication or group of complications, whether critical or non-critical, between groups (5).

\section{DISCUSSION}

There was no statistical difference for patients receiving hypothermia and mortality and also for good neurological outcome 
(GOS score of 4 or 5 ) in the 7 clinical trials. We found some interesting points, analyzed the mechanism and provided our speculation. Two Chinese studies showed that hypothermia treatment had better effects on Asian patients, and this seems related to controlled hypothermia at a little higher temperature $\left(33-36^{\circ} \mathrm{C}\right)(10,20)$. There was no significant difference of prognosis in the induced hypothermia group $\left(35-36^{\circ} \mathrm{C}\right)$ and mild hypothermia group $\left(33-34^{\circ} \mathrm{C}\right)$, but these two groups had a much better prognosis than the control group. Regarding complications, the induced hypothermia group and the control group had no significant difference, but were much better than the mild hypothermia group. The hypothermia treatment on TBI seems had good outcomes on focal lesions, in adult patients. We try to explain this finding (Figures 4, 5). First, in the 2001 Clifton's trial, there was an average delay of 8.4 hours in attaining the target temperature. The subgroup of patients in this trial who were initially hypothermic and then randomized to hypothermia had a significant long-term neurological advantage compared to normothermia (8). While Clifton's second randomized trial in 2011 achieved faster and earlier induction of hypothermia, other limitations again probably negated any benefit achieved by this study design improvement. However, any future trial should aim to achieve hypothermia as early as possible and ideally at the location of the traumatic event. Second, in severe TBI the generalized swelling of brain tissue frequently persists for over 48 hours. It is therefore likely that therapeutic levels of hypothermia lasting for only 48 hours were insufficient. This assertion is supported by evidence from several meta-analyses including the brain trauma foundation (BTF) meta-analysis finding that trials of prophylactic hypothermia longer than 48 hours were associated with significantly reduced mortality (9). The pathophysiology of TBI helps to explain why there may be benefit to performing hypothermia beyond 48 hours. In a recent observational research of ICP after TBI, only one-third of patients achieved their peak ICP within the first 2 days after injury, and 20\% did not achieve their highest ICP until after day 5. A number of studies have reported a rebound increase in ICP associated with the discontinuation of cooling, perhaps negating any benefit accrued during the first 48 hours of cooling. In earlier studies, a 24-48 hour duration of cooling was chosen because of concerns that longer periods of hypothermia would be associated with increased risk of adverse events. However, increased duration of hypothermia has not been shown to increase risk of delayed hemorrhage or pneumonia. Future trials investigating the protective effects of therapeutic hypothermia should ensure hypothermia is maintained in excess of 48 hours. Further research may elucidate whether earlier implementation of hypothermia therapy or more prolonged hypothermia therapy would improve the outcome with severe TBI. Third, the Clifton's trials withdrew hypothermia on a time-based trigger rather than according to a physiological trigger. Rewarming of patients despite ongoing increases in ICP is not considered optimal clinical practice (16). Hypothermia should ideally be withdrawn using a physiological trigger and over a gradual period to avoid uncontrolled intracranial hypertension. The 2 Chinese studies withdrew hypothermia according to a physiological trigger (ICP) and over a gradual period to avoid intracranial hypertension. And the results of these 2 studies showed that the prognosis of hypothermia group was much better than the control group. Future research may shed new light on this field.

\section{CONCLUSION}

The results of these clinical trials suggest that the effects of hypothermia on TBI were heterogeneous. Hypothermia treatment for TBI seems to provide good outcomes in focal lesions in adult patients, Asian patients, and at a relatively higher temperature $\left(33-36^{\circ} \mathrm{C}\right)$.

\section{REFERENCES}

1. Andrews PJ, Sinclair HL, Rodriguez A, Harris BA, Battison CG, Rhodes JK, Murray GD; Eurotherm3235 Trial Collaborators: Hypothermia for intracranial hypertension after traumatic brain injury. N Engl J Med 373(25):2403-2412, 2015

2. Bernard SA, Gray TW, Buist MD, Jones BM, Silvester W, Gutteridge G, Smith K: Treatment of comatose survivors of out-of-hospital cardiac arrest with induced hypothermia. $\mathrm{N}$ Engl J Med 346:557-563, 2002

3. Chatzipanteli K, Alonso OF, Kraydieh S: Importance of posttraumatic hypothermia and hyperthermia on the inflammatory response after fluid percussion brain injury: Biochemical and immunocytochemical studies. J Cereb Blood Flow Metab 20:531-542, 2000

4. Cheung KW, Green RS, Magee KD: Systematic review of randomized controlled trials of therapeutic hypothermia as a neuroprotectant in post-cardiac arrest patients. CJEM 8:329337, 2006

5. Clifton GL, Miller ER, Choi SC, Levin HS, McCauley S, Smith KR Jr, Muizelaar JP, Marion DW, Luerssen TG: Hypothermia on admission in patients with severe brain injury. J Neurotrauma 19(3): 293-301, 2001

6. Clifton GL, Miller ER, Choi SC, Levin HS, McCauley S, Smith KR Jr, Muizelaar JP, Wagner FC Jr, Marion DW, Luerssen TG, Chesnut RM, Schwartz M: Lack of effect of induction of hypothermia after acute brain injury. N Engl J Med 344(8): 556-563, 2001.

7. Clifton GL, Valadka A, Zygun D, Coffey CS, Drever P, Fourwinds S, Janis LS, Wilde E, Taylor P, Harshman K, Conley A, Puccio A, Levin HS, McCauley SR, Bucholz RD, Smith KR, Schmidt $\mathrm{JH}$, Scott JN, Yonas H, Okonkwo DO: Very early hypothermia induction in patients with severe brain injury (the National Acute Brain Injury Study: Hypothermia II): A randomised trial. Lancet Neurol 10(2):131-139, 2011

8. Coles JP, Fryer TD, Smielewski P, Rice K, Clark JC, Pickard JD, Menon DK: Defining ischemic burden after traumatic brain injury using 150 PET imaging of cerebral physiology. J Cereb Blood Flow Metab 24:191-201, 2004

9. Corwin HL, Gettinger A, Fabian TC, May A, Pearl RG, Heard $\mathrm{S}$, An R, Bowers PJ, Burton P, Klausner MA, Corwin MJ; EPO Critical Care Trials Group: Efficacy and safety of epoetin alfa in critically ill patients. N Engl J Med 357(10):965-976, 2007

10. Gengsheng L, You M: Hypothermia effect patient with traumatic brain injury in coagulation, fibrinolysis and inflammation. Chin J Cell Mol Immunol 26(4):385-386, 2010 
11. Hutchinson JS, Ward RE, Lacroix J, Hébert PC, Barnes MA, Bohn DJ, Dirks PB, Doucette S, Fergusson D, Gottesman R, Joffe AR, Kirpalani HM, Meyer PG, Morris KP, Moher D, Singh RN, Skippen PW; Hypothermia Pediatric Head Injury Trial Investigators and the Canadian Critical Care Trials Group: Hypothermia therapy after traumatic brain injury in children. N Engl J Med 358(23):2447-2456, 2008

12. Hypothermia after Cardiac Arrest Study Group: Mild therapeutic hypothermia to improve the neurologic outcome after cardiac arrest. N Engl J Med 346:549-556, 2002

13. Inoue $Y$, Shiozaki T, Tasaki $O$, Hayakata T, Ikegawa $H$, Yoshiya $\mathrm{K}$, Fujinaka T, Tanaka $\mathrm{H}$, Shimazu T, Sugimoto $\mathrm{H}$ : Changes in cerebral blood flow from the acute to the chronic phase of severe head injury. J Neurotrauma 22:1411-1418, 2005

14. Jiang JY, Lyeth BG, Kapasi MZ, Jenkins LW, Povlishock JT: Moderate hypothermia reduces blood-brain barrier disruption following traumatic brain injury in the rat. Acta Neuropathol 84:495-500, 1992

15. Marion DW, Penrod LE, Kelsey SF, Obrist WD, Kochanek PM, Palmer AM, Wisniewski SR, DeKosky ST: Treatment of traumatic brain injury with moderate hypothermia. $\mathrm{N}$ Engl $\mathrm{J}$ Med 20:540-546, 1997
16. Narayan RK, Michel ME, Ansell B: Clinical trials in head injury. J Neurotrauma 19(5):503-557, 2002

17. Tokutomi T, Morimoto K, Miyagi T, Yamaguchi S, Ishikawa $\mathrm{K}$, Shigemori M: Optimal temperature for the management of severe traumatic brain injury: Effect of hypothermia on intracranial pressure, systemic and intracranial hemodynamics, and metabolism. Neurosurgery 52:102-111, discussion 111112,2003

18. Werner $\mathrm{C}$, Engelhard $\mathrm{K}$ : Pathophysiology of traumatic brain injury. Br J Anaesth 99:4-9, 2007

19. Whalen MJ, Carlos TM, Clark RS, Marion DW, DeKosky MS, Heineman S, Schiding JK, Memarzadeh F, Dixon CE, Kochanek PM: The relationship between brain temperature and neutrophil accumulation after traumatic brain injury in rats. Acta Neurochir Suppl 70:260-261, 1997

20. Zhihong $X$, Chunyang $\mathrm{CH}$, Peng $\mathrm{P}$ : Induced hypothermia after traumatic brain injury. Chin J Clin Neurosur 12(9):555-556, 2007 